\title{
Natural history of diabetic macular edema and factors predicting outcomes in sham-treated patients (MEAD study)
}

\author{
Young Hee Yoon ${ }^{1} \cdot$ David S. Boyer $^{2} \cdot$ Raj K. Maturi $^{3,4} \cdot$ Francesco Bandello $^{5} \cdot$ Rubens Belfort Jr $^{6} \cdot$ Albert J. Augustin $^{7}$. \\ Xiao-Yan $\mathrm{Li}^{8} \cdot$ Zhanying Bai $^{9} \cdot$ Yehia Hashad $^{8}$ - on behalf of the Ozurdex MEAD Study Group
}

Received: 15 May 2019 / Revised: 25 August 2019 / Accepted: 4 September 2019 /Published online: 25 October 2019

(C) The Author(s) 2019

\begin{abstract}
Purpose To describe the natural history of diabetic macular edema (DME) with respect to best-corrected visual acuity (BCVA) and central retinal thickness (CRT) outcomes and to identify baseline patient characteristics and systemic factors associated with improvement or worsening of outcomes in sham-treated patients.

Methods The study population was sham-treated patients $(n=350)$ in the 3 -year MEAD registration study of dexamethasone intravitreal implant for treatment of DME. Patients had center-involved DME and received sham intravitreal injections in the study eye at $\geq 6$-month intervals. Potential prognostic factors for outcomes were evaluated using multiple linear regression analysis.

Results Visual and anatomic outcomes were poorer in patients who left the study early $(n=198)$ than in study completers $(n=$ 152). Mean change in BCVA from baseline at the last visit with available data was +0.9 letters; $37.5 \%$ of patients had no change in BCVA, 23.2\% had gained $>10$ letters, and $16.0 \%$ had lost $>10$ letters. Older age and baseline diabetic retinopathy score $>6$ were associated with worse BCVA outcomes; thicker baseline CRT and larger number of hypertension medications used were associated with larger reductions in CRT during the study.

Conclusions BCVA and CRT outcomes were variable in this population of DME patients with generally good glycemic control. In DME patients without active treatment, older age and baseline diabetic retinopathy score $>6$ were associated with less improvement in BCVA; thicker baseline CRT and a larger number of antihypertensive medications used predicted better improvement in CRT.

Trial registration The MEAD study trials are registered at ClinicalTrials.gov with the identifiers NCT00168337 and NCT00168389.
\end{abstract}

Keywords Diabetic macular edema $\cdot$ Natural history $\cdot$ Prognosis $\cdot$ Risk factors $\cdot$ Visual acuity

MEAD study group members are listed in Appendix 1.

Electronic supplementary material The online version of this article (https://doi.org/10.1007/s00417-019-04464-2) contains supplementary material, which is available to authorized users.

Young Hee Yoon

yhyoon@amc.seoul.kr

1 Department of Ophthalmology, Asan Medical Center, 88 Olympic-ro 43-gil, Songpa-gu, Seoul, South Korea

2 Retina-Vitreous Associates Medical Group, Los Angeles, CA, USA

3 Midwest Eye Institute, Indianapolis, IN, USA

4 Department of Ophthalmology, Indiana University School of Medicine, Indianapolis, IN, USA
5 Hospital San Raffaele, University Vita-Salute, Milan, Italy

6 Vision Institute, Federal University of São Paulo, São Paulo, Brazil

7 Department of Ophthalmology, Staedtisches Klinikum Karlsruhe, Karlsruhe, Germany

Allergan plc, Irvine, CA, USA

$9 \quad$ Allergan plc, Bridgewater, NJ, USA 


\section{Introduction}

Diabetic macular edema (DME) is a manifestation of diabetic retinopathy (DR) and the major cause of central vision loss among patients with DR. The pathogenesis of DME, although not completely understood, is believed to involve multiple interacting pathways related to hyperglycemia [1]. Free radical and advanced glycation end products, inflammatory processes, and vascular endothelial growth factor (VEGF) have all been implicated in the breakdown of the blood-retinal barrier that results in vascular leakage and retinal thickening in DME $[1,2]$. A moderate negative correlation has been demonstrated between central retinal thickness (CRT) measured on optical coherence tomography (OCT) and best-corrected visual acuity (BCVA) in patients with DME [3].

Several systemic risk factors for the development of DME have been identified. A meta-analysis of results from 20 population-based studies, in which DR and DME were determined from fundus photographs using consistent, rigorous methods, identified a longer duration of diabetes, higher glycosylated hemoglobin (HbAlc) levels, and hypertension as significant risk factors for DME in adults with diabetes [4]. There was also an association between higher blood cholesterol levels (total cholesterol $\geq 4 \mathrm{mmol} / \mathrm{L}$ ) and a higher prevalence of DME [4]. Total-to-HDL (high-density lipoproteins) ratio and LDL (low-density lipoproteins) have also been shown to be significant risk factors for the development of DME [5]. Consistent with these findings, in a recent study using a health claims database, lipid-lowering medication use was associated with a decreased incidence of DME [6]. Other potential systemic risk factors for DME include age, sleep apnea, pregnancy, anemia, lack of glycemic control, duration of diabetes, nephropathy/microalbuminuria, systemic fluid retention in congestive heart failure or renal disease, and use of the glitazone (thiazolidinedione) class of oral antihyperglycemic medications [7-11].

Systemic factors such as lack of glycemic control might also be associated with the severity of DME and with visual and anatomic outcomes after treatment. In a prospective study in 52 patients with DME, higher HbA1c was associated with both worse CRT and worse BCVA [12]. Higher HbA1c was also associated with worse CRT after surgical treatment (pars plana vitrectomy with internal limiting membrane peeling) of 44 eyes with DME [13]. In a retrospective series of 124 patients with DME treated with anti-VEGF therapy, patients with lower $\mathrm{HbAlc}$ at baseline demonstrated better improvement in both BCVA and CRT after anti-VEGF treatment [14]. However, in the RISE/RIDE registration studies of ranibizumab for treatment of DME, no associations were found between baseline systemic factors (including $\mathrm{HbAlc}$ and blood pressure) and BCVA improvement after 24 months of treatment [15]. Baseline HbA1c in the RISE/RIDE studies was required to be $\leq 12 \%$ [16], and there were no differences in outcomes among ranibizumab-treated patients in the 4 quartiles of baseline $\mathrm{HbA1c}(\leq 6.6 \%,>6.6$ to $7.4 \%,>7.4$ to $8.5 \%$, and $>8.5 \%$ ) [17].

Current therapy for diabetes aims for glycemic control and management of hypertension and serum lipids to decrease the risk of complications including DME [18]. However, the extent to which systemic factors such as hypertension and hyperlipidemia might exacerbate pre-existing DME has not been well studied. The objectives of this study were to describe the natural history of DME with respect to BCVA and CRT outcomes and to identify baseline patient characteristics and systemic factors that are associated with improvement or worsening of outcomes in patients with no active treatment. The study population was the sham treatment group of the 3-year MEAD registration study [19] of dexamethasone intravitreal implant for treatment of DME.

\section{Methods}

This was a post hoc analysis of efficacy outcomes and factors associated with efficacy outcomes in patients assigned to the sham group in the 3-year, randomized, multicenter, doublemasked registration study (MEAD) of dexamethasone intravitreal implant for treatment of DME. The MEAD study was conducted from February 2005 to June 2012 at 131 sites in 22 countries. The study comprised two trials (ClinicalTrials.gov NCT00168337 and NCT00168389) with identical protocols, and the results were pooled for analysis. The study methods and patient selection were reported previously [19-22] and are described briefly below. The study was conducted in accordance with the principles of the Declaration of Helsinki, and the study protocol was approved by an institutional review board or independent ethics committee at each site. All patients provided written informed consent.

Patients included in the study were adults diagnosed with type 1 or 2 diabetes mellitus and fovea-involved macular edema. BCVA in the study eye, measured with the Early Treatment Diabetic Retinopathy Study (ETDRS) method, was required to be between 34 and 68 letters (20/200 and 20/50), and CRT in the 1-mm central macular subfield of the study eye was required to be $\geq 300 \mu \mathrm{m}$ on time-domain OCT. Key exclusion criteria included uncontrolled diabetes $(\mathrm{HbA} 1 \mathrm{c}$ $>10 \%$ ) or other systemic disease, glomerular filtration rate (GFR) $<50 \mathrm{~mL} / \mathrm{min}$, treatment with intravitreal anti-VEGF within the 3 months before study entry, treatment with intravitreal triamcinolone within the 6 months before study entry, intraocular laser treatment within the 90 days before study entry, a history of pars plana vitrectomy in the study eye, and active iris or retinal neovascularization in the study eye.

Patients in the sham group received sham procedure (a needleless implant applicator was pressed against the conjunctiva of the study eye) no more frequently than every 
6 months. Patients were followed for 36 or 39 months. All patients who required rescue treatment in the study eye were exited from the study before receiving the rescue treatment. Patients who had a loss in BCVA from baseline of 15 or more letters in the study eye, which was confirmed at two consecutive visits at least 4 weeks apart, were exited from the study at the discretion of the investigator. The main efficacy measures were BCVA in the study eye, measured with the ETDRS method at every study visit, and CRT in the 1-mm central macular subfield of the study eye, measured with timedomain OCT (Stratus OCT2 or OCT3) every 3 months. OCT images were evaluated by a central reading center (University of Wisconsin Fundus Photograph Reading Center, Madison, WI). DR was graded using the ETDRS Final Retinopathy Severity Scale [23] condensed to 9 severity categories [21], with scores of $\leq 6$ representing severity up to severe nonproliferative DR (NPDR) and scores $>6$ representing mild proliferative DR (PDR) or worse severity.

All analyses in the present report used observed values, with no imputation for missing values, in the intent-to-treat population. Visual outcomes analyzed in study eyes were mean change in BCVA from baseline at each study visit, percentage of patients with at least 15-letter improvement in BCVA, distribution of patients by BCVA change from baseline ( $>10$-letter gain, $5-10$-letter gain, no change $[<5$ letters gain or loss], 5-10-letter loss, or $>10$-letter loss), and average change in BCVA from baseline during the study period evaluated with the time-adjusted area-under-the-curve (AUC) approach. Anatomic outcomes evaluated in study eyes were mean change in CRT from baseline at each study visit, percentage change in CRT from baseline in patients stratified by baseline CRT $(\leq 400$ or $>400 \mu \mathrm{m})$, percentage of patients with CRT $<300 \mu \mathrm{m}$, and percentage of patients with at least two-step progression in DR severity from baseline. Additional analyses compared blood pressure, HbA1c, and GFR change from baseline at study exit between patients who discontinued from the study and patients who completed the study. Time to discontinuation because of lack of efficacy was evaluated with Kaplan-Meier survival analysis.

Multiple linear regression analysis was used to evaluate potential prognostic factors of BCVA change from baseline to the last available visit, average BCVA change from baseline during the study (AUC approach), and CRT change from baseline at the last available visit. The final models were developed using the stepwise selection method with the entry $P$ value criterion set at 0.10 . The variables evaluated as potential factors in the models were baseline patient characteristics including demographics (age, race, gender), body mass index (BMI), HbAlc ( $\leq 8 \%$ vs $>8 \%$ ), systolic blood pressure, diastolic blood pressure, GFR, duration of diabetes, history of hypertension, and history of hypercholesterolemia; baseline study eye characteristics including lens status, DR severity ( $\leq 6 \mathrm{vs}>6$ ), duration of DME, previous treatment for DME, and BCVA (in the models for BCVA change from baseline) or CRT (in the model for CRT change from baseline); and parameters during the study including use of aspirin or other platelet aggregation inhibitor, use of glitazone, use of medication to treat dyslipidemia, adverse event reports of dyslipidemia (blood cholesterol increased, blood triglycerides increased, low-density lipoprotein increased, hypercholesterolemia, dyslipidemia, hyperlipidemia, or hypertriglyceridemia), number of antihypertensive medications used, and change in $\mathrm{HbA1c}$ from baseline at the last visit. Platelet aggregation inhibitors, glitazones, medications used to treat dyslipidemia, and antihypertensive medications are listed in Appendix 2. All analyses were performed using SAS software version 9.3 (SAS Inc., Cary, NC).

\section{Results}

Baseline characteristics of the 350 patients in the sham group of the MEAD study are listed in Table 1. The attrition rate was high in large part because of the requirement for patients to exit the study before receiving rescue treatment. Within the sham group, $152(43.4 \%)$ patients completed the 3-year study and 198 (56.6\%) patients discontinued from the study; the most common reason for early exit from the study was lack of efficacy (84 [24.0\%] patients). Kaplan-Meier analysis indicated that the rate of discontinuations because of lack of efficacy was highest at months 6 and 12 (Fig. 1).

Analysis of blood pressure, $\mathrm{HbA1c}$, and GFR change from baseline at the last available visit showed no clinically significant differences in these parameters between sham patients who left the study early $(n=198)$ and sham patients who completed the study $(n=152)$ (Table 2). In contrast, visual and anatomic outcomes at the last available visit were poorer in patients who left the study early than in patients who completed the study (Table 2). At baseline, patients who left the study early and patients who completed the study had similar mean BCVA (56.7 and 57.2 letters, respectively) and CRT (476 and $442 \mu \mathrm{m}$, respectively). However, at the last available visit, mean BCVA was 54.1 and 62.0 letters, respectively, and mean CRT was 458 and $308 \mu \mathrm{m}$, respectively (Table 2).

Mean (median) $\mathrm{HbA} 1 \mathrm{c}$ for all patients was $7.5 \%(7.3 \%)$ at baseline $(n=349)$ and $7.8 \%(7.6 \%)$ at the study end $(n=147)$.

\section{Visual outcomes}

Analysis of the mean change in BCVA from baseline at scheduled study visits showed a small but significant improvement in BCVA in sham-treated patients throughout the study. Mean changes in BCVA from baseline were similar regardless of baseline lens status (phakic or pseudophakic) (Fig. 2a). The mean improvement in BCVA was approximately 1-3 letters during the first 12 months of the study and increased during 
Table 1 Baseline patient characteristics

\begin{tabular}{|c|c|}
\hline Characteristic & Patients $(n=350$ \\
\hline Age, mean (SD), years & $62.5(9.5)$ \\
\hline [Range] & {$[26-88]$} \\
\hline Male, $n(\%)$ & $217(62.0)$ \\
\hline \multicolumn{2}{|l|}{ Race/ethnicity, $n(\%)$} \\
\hline Asian (excludes Japanese) & $53(15.1)$ \\
\hline Black & $20(5.7)$ \\
\hline Caucasian & $233(66.6)$ \\
\hline Hispanic & $33(9.4)$ \\
\hline Japanese & $1(0.3)$ \\
\hline Other & $10(2.9)$ \\
\hline Height, mean (SD), cm & $165.9(9.2)$ \\
\hline Weight, mean (SD), kg & $80.5(17.6)$ \\
\hline \multicolumn{2}{|l|}{ Type of diabetes } \\
\hline Type I & $28(8.0)$ \\
\hline Type II & $322(92.0)$ \\
\hline Duration of diabetes, mean (SD), years & $15.9(9.1)$ \\
\hline $\mathrm{HbA} 1 \mathrm{c}$, mean $(\mathrm{SD}), \%$ & $7.5(1.1)$ \\
\hline$\leq 8 \%, n(\%)$ & $249(71.1)$ \\
\hline$>8 \%, n(\%)$ & $100(28.6)$ \\
\hline Data not available & $1(0.3)$ \\
\hline Glomerular filtration rate, mean $(\mathrm{SD}), \mathrm{mL} / \mathrm{min}$ & $86.8(25.6)$ \\
\hline Systolic blood pressure, mean (SD), $\mathrm{mm} \mathrm{Hg}$ & $137.2(17.2)$ \\
\hline Diastolic blood pressure, mean (SD), $\mathrm{mm} \mathrm{Hg}$ & $78.5(10.2)$ \\
\hline History of hypertension, $n(\%)$ & $258(73.7)$ \\
\hline History of hypercholesterolemia, $n(\%)$ & $93(26.6)$ \\
\hline BCVA in study eye, mean (SD), ETDRS letters & $56.9(8.7)$ \\
\hline CRT in study eye, mean (SD), $\mu \mathrm{m}$ & $460.9(132.6)$ \\
\hline Duration of DME in study eye, mean (SD), months & $25.9(27.3)$ \\
\hline [Range] & {$[0-187]$} \\
\hline \multicolumn{2}{|l|}{ Previous treatment for DME in study eye, $n(\%)$} \\
\hline Focal/grid laser & $243(69.4)$ \\
\hline Intravitreal steroid & $61(17.4)$ \\
\hline Anti-VEGF & $26(7.4)$ \\
\hline None & $89(25.4)$ \\
\hline \multicolumn{2}{|l|}{ DME perfusion status in study eye } \\
\hline Ischemic & $27(7.7)$ \\
\hline Non-ischemic & $284(81.1)$ \\
\hline Data not available & $39(11.1)$ \\
\hline \multicolumn{2}{|l|}{ DR severity score in study eye, $n(\%)$} \\
\hline$\leq 6$ (severe NPDR or better $)$ & $200(57.1)$ \\
\hline$>6$ (mild PDR or worse) & $123(35.1)$ \\
\hline Data not available & $27(7.7)$ \\
\hline \multicolumn{2}{|l|}{ Lens status in study eye, $n(\%)$} \\
\hline Phakic & $249(71.1)$ \\
\hline Pseudophakic & $101(28.9)$ \\
\hline
\end{tabular}

$B C V A$ best-corrected visual acuity, $B M I$ body mass index, $C R T$ central retinal thickness, $D M E$ diabetic macular edema, $D R$ diabetic retinopathy, ETDRS Early Treatment Diabetic Retinopathy Study, HbAlc glycosylated hemoglobin, NPDR nonproliferative diabetic retinopathy, $P D R$ proliferative diabetic retinopathy, $S D$ standard deviation, $V E G F$ vascular endothelial growth factor

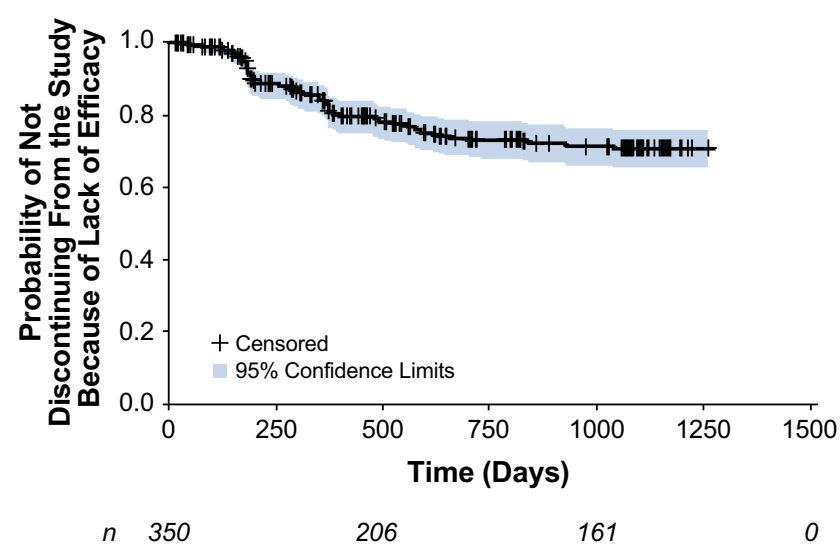

Fig. 1 Kaplan-Meier analysis of time to patient discontinuation from the study because of lack of efficacy. At the end of follow-up, the estimated probability of discontinuing from the study because of lack of efficacy was $29 \%$

the second and the third year of the study (Fig. 2a). However, this increase resulted from patient selection rather than from continued improvement in BCVA, because almost half of the sham-treated patients had discontinued from the study by month 15 , and BCVA outcomes on average were poorer in patients who discontinued from the study than in patients who completed the study (Fig. 2b). The mean ( \pm SD) change in BCVA from baseline in sham-treated patients using last available postbaseline data (usually collected at the month $36 / 39$ or early exit visit) was $+4.8 \pm 13.0$ letters (range -57 to +30 , $n=152$ ) in patients who completed the study and $-2.8 \pm 13.5$ letters (range -66 to $+29, n=188$ ) in patients who exited the study early. The mean $( \pm \mathrm{SD})$ change in BCVA from baseline among all sham-treated patients at their last visit with available data was $+0.9 \pm 13.2$ letters $(n=349)$.

Favorable visual outcomes in some patients despite the lack of active treatment were also seen in the analysis of percentage of patients who had at least 15-letter BCVA gains from baseline. On average, patients in the sham group had at least 15-letter BCVA improvement from baseline at $9.7 \%$ of their follow-up visits (range 0 to $100 \%$ ). The mean (standard error of the mean, SEM) average change in BCVA from baseline during the study in sham-treated patients, evaluated using the AUC approach, was 2.0 (0.43) letters [19].

Evaluation of the distribution of patients with gain, loss, or no change ( $<5$ letters) in BCVA from baseline showed that at each visit, $<20 \%$ of patients with available data had a loss in BCVA of 5 letters or more (Fig. 3). The percentage of patients with a $>10$-letter gain in BCVA increased during the study period, consistent with the findings that on average, patients who exited the study early had poorer BCVA outcomes. At their last visit with available data (typically at month 36/39 or early exit, $n=349$ ), $37.5 \%$ of patients had no change in BCVA from baseline, $14.3 \%$ had a 5-10-letter gain, $23.2 \%$ had a $>10$-letter gain, $8.9 \%$ had a 5-10-letter loss, and $16.0 \%$ had a $>10$-letter loss. 
Table 2 Parameters in patients who exited the study early and patients who completed the study

\begin{tabular}{lcc}
\hline Parameter, mean (SD) & $\begin{array}{l}\text { Patients who exited the study } \\
\text { early }(n=198)\end{array}$ & $\begin{array}{l}\text { Patients who completed the } \\
\text { study }(n=152)\end{array}$ \\
\hline At baseline & $56.7(8.75)$ & $57.2(8.66)$ \\
BCVA, letters & $476(135)$ & $442(127)$ \\
CRT, $\mu \mathrm{m}$ & $54.1(14.3)$ & $62.0(14.5)$ \\
At last available visit & $458(196)$ & $308(164)$ \\
BCVA, letters & $-1.1(17.9)$ & $-2.0(16.5)$ \\
CRT, $\mu \mathrm{m}$ & $-0.0(12.1)$ & $-2.2(10.3)$ \\
$\begin{array}{l}\text { Systolic blood pressure change from } \\
\text { baseline, mm Hg }\end{array}$ & $0.1(1.1)$ & $0.3(1.2)$ \\
$\begin{array}{l}\text { Diastolic blood pressure change from } \\
\text { baseline, mm Hg }\end{array}$ & $-8.0(19.3)$ & $-9.7(15.8)$ \\
$\begin{array}{l}\text { HbA1c change from baseline, } \% \\
\text { GFR change from baseline, } \mathrm{mL} / \mathrm{min}\end{array}$ & \\
\hline
\end{tabular}

$B C V A$ best-corrected visual acuity, $C R T$ central retinal thickness, GFR glomerular filtration rate, $H b A l c$ glycosylated hemoglobin, $S D$ standard deviation

\section{Anatomic outcomes}

Analysis of the mean change in CRT from baseline at scheduled visits suggested continual improvement in CRT through month 33 of the study, when the mean change in CRT from baseline was $-150 \mu \mathrm{m}$ (Fig. 4). However, almost two thirds of patients had missing data at month 33, and the early exit of sham patients with less favorable anatomic improvement resulted in greater apparent improvement in CRT in the remaining patients at visits in the second and the third year of the study. The mean $( \pm \mathrm{SD})$ change in CRT from baseline using last available postbaseline data was $-131 \pm 173 \mu \mathrm{m}$ in patients who completed the study (range -783 to $+462, n=$ 148 ) and $-12 \pm 171 \mu \mathrm{m}$ in patients who exited the study early (range -479 to $+478, n=178$ ).

The percentage change in CRT from baseline was greater in patients with baseline CRT $>400 \mu \mathrm{m}$ than in patients with baseline CRT $\leq 400 \mu \mathrm{m}$ (Fig. 5). For patients with baseline CRT $>400 \mu \mathrm{m}$, mean CRT at baseline was $536 \mu \mathrm{m}$, and the mean $( \pm \mathrm{SD})$ percentage change in CRT from baseline at patients' final postbaseline evaluation was $-20.1 \% \pm 33.3 \%$ $(n=196)$. For patients with baseline CRT $\leq 400 \mu \mathrm{m}$, mean CRT at baseline was $328 \mu \mathrm{m}$, and the mean $( \pm \mathrm{SD})$ percentage change in CRT from baseline at patients' final postbaseline evaluation was $-2.2 \% \pm 45.3 \%(n=120)$.

The percentage of patients with CRT $<300 \mu \mathrm{m}$ in the study eye increased during the study period (figure in Online Resource 1). At their last visit with data available, CRT in the study eye was $<300 \mu \mathrm{m}$ in $41.5 \%$ of patients.

The figure in Online Resource 2 shows the mean change in DR severity from baseline at follow-up evaluations. Among all patients with DR severity assessed and recorded, only $6.5 \%$ (16 of 248 patients) had at least a two-step increase in DR severity from baseline at their last visit with data available.

\section{Factors predictive of outcomes}

Table 3 shows the full model of factors associated with BCVA change from baseline at the last available visit. Age, hypertension, baseline DR severity score, and baseline BCVA were identified as significant prognostic factors in the final model after stepwise selection (Table 4). BCVA gain from baseline at the last visit was 5.8 letters worse in patients with a history of hypertension versus patients with no history of hypertension. Older patients also had less favorable BCVA outcomes: each 10 -year increase in patient age was associated with 2.9 letters worse BCVA gain from baseline at the last visit. Less severe DR was associated with better improvement in BCVA: a DR severity score of $\leq 6$ at baseline was associated with 4.3 letters greater BCVA gain at the last visit compared with a DR severity score of $>6$. A 10-letter higher BCVA score at baseline was associated with 2.8 letters worse BCVA gain from baseline at the last visit, suggesting a possible ceiling effect.

The full model of factors associated with the average BCVA change from baseline during the study (AUC approach) is shown in Table 5. Similar to the final model for BCVA change from baseline at the last visit, the final model for average BCVA change from baseline identified age, baseline DR severity score, and baseline BCVA as significant prognostic factors (Table 6). Each 10-year increase in patient age was associated with 1.6 letters less average gain in BCVA during the study, a DR severity score $\leq 6$ at baseline was associated with 3.2 letters greater average BCVA improvement during the study, and a 10-letter higher BCVA score at baseline was associated with 2.1 letters worse average improvement in BCVA during the study, again suggesting a possible ceiling effect.

Table 7 shows the full model for the change in CRT from baseline at the last available visit. Age, baseline GFR, baseline CRT, and number of antihypertensive medications used 

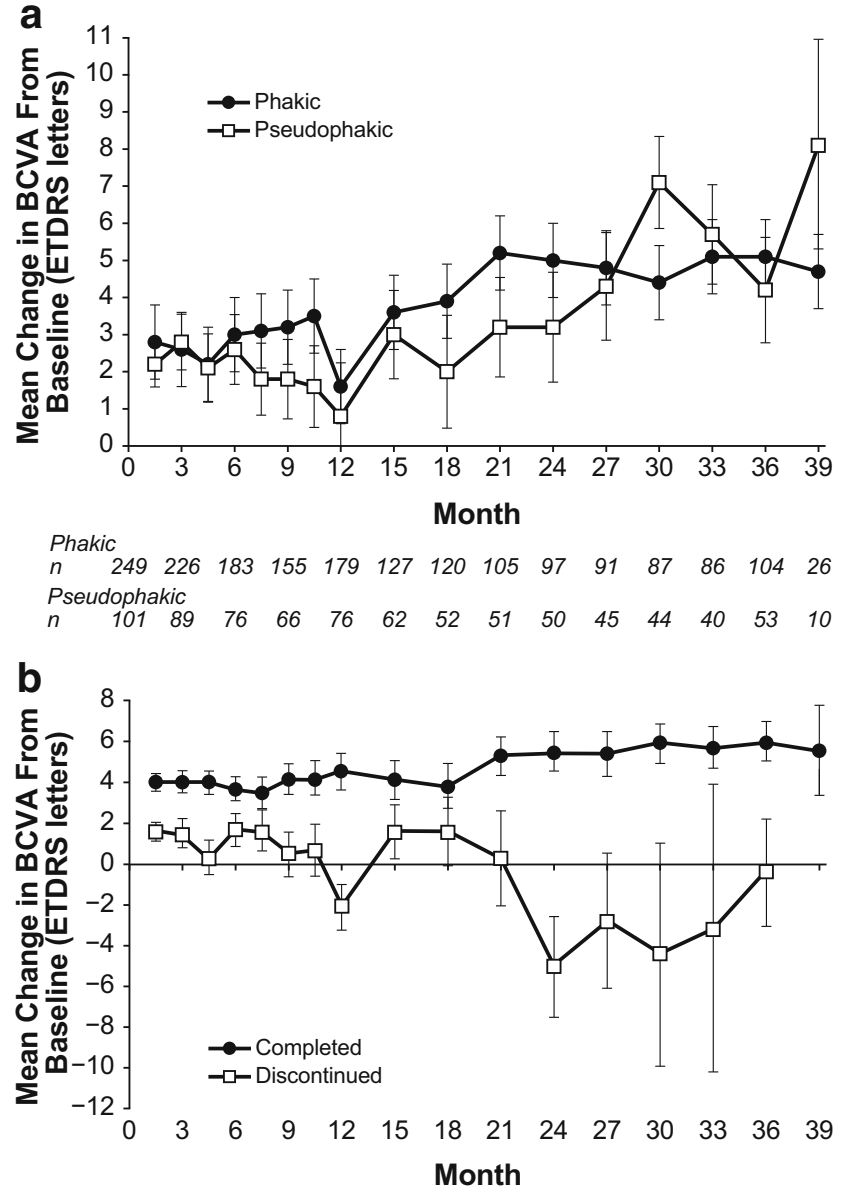

Patients who completed the study

$\begin{array}{lllllllllllllll}n & 152 & 150 & 150 & 137 & 134 & 137 & 136 & 135 & 131 & 123 & 124 & 121 & 127 & 36\end{array}$

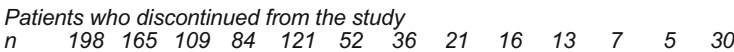

Fig. 2 Mean change in BCVA from baseline in the study eye of a shamtreated patients stratified by baseline lens status and $\mathbf{b}$ sham-treated patients stratified by study completion status. Mean baseline BCVA in study eyes was 56.9 letters ( $\sim 20 / 70$ Snellen equivalent $)$ in all patients, 57.3 letters in baseline phakic patients, 56.0 letters in baseline pseudophakic patients, 57.2 letters in patients who completed the study, and 56.7 letters in patients who discontinued from the study. Analysis is based on observed values with no imputation for missing values. Error bars indicate the standard error of the mean. BCVA, best-corrected visual acuity; ETDRS, Early Treatment Diabetic Retinopathy Study

during the study period were identified as significant prognostic factors in the final model after stepwise selection (Table 8). Older patients had less improvement in CRT: each 10-year increase in patient age was associated with a $32-\mu \mathrm{m}$ less reduction in CRT from baseline at the last visit. Higher baseline GFR also predicted less reduction in CRT from baseline at the last visit, with each $10 \mathrm{~mL} / \mathrm{min}$ increase in baseline GFR associated with an $11-\mu \mathrm{m}$ less reduction in CRT from baseline. Thicker baseline CRT predicted better reduction in CRT, with each $10-\mu \mathrm{m}$ increase in CRT at baseline associated with a 4.6- $\mu \mathrm{m}$ greater reduction in CRT from baseline at the last visit. Use of antihypertensive medications during the study was also associated with better improvement in CRT: each additional medication used was associated with a $16-\mu \mathrm{m}$ greater reduction in CRT from baseline at the last visit.

\section{Discussion}

The present analysis evaluated BCVA and CRT outcomes in sham-treated patients with DME followed for up to month 36/ 39 in the MEAD study. The results showed significant variability in the natural history of DME in these patients. At each visit during the first year of follow-up, patients were most likely to have no change in BCVA from baseline, but some patients had significant improvement in BCVA of more than 10 letters, and others had significant worsening in BCVA of more than 10 letters. Patients with poorer outcomes tended to exit the study early to receive rescue treatment. Baseline factors significantly associated with greater improvement in BCVA in the patients were younger age, lower DR severity score, and lower BCVA. The absence of a history of hypertension was also significantly associated with greater improvement in BCVA at the last available visit. With respect to anatomic outcomes, baseline factors associated with greater reduction in CRT from baseline were younger age, lower baseline GFR, and thicker CRT. Use of a larger number of antihypertensive medications during the study predicted better improvement in CRT.

Because of the availability of effective pharmacologic treatments for DME, we anticipate that there will not be opportunities in the future to study the natural history of DME and investigate relationships of systemic factors to improvement or worsening of DME in untreated patients. The sham group in the MEAD study, comprising patients who underwent sham procedures to maintain masking of patients and investigators, may be the last study population with DME that is followed for years without any active treatment, and that, therefore, could provide information regarding the natural history of DME. Changes in BCVA from baseline were similar in baseline phakic and pseudophakic eyes in these patients, suggesting that cataract development and surgery were not significant factors affecting BCVA outcomes. At their last visit with data available, $41.5 \%$ of patients had achieved CRT of $<300 \mu \mathrm{m}$ and $23.2 \%$ of patients had achieved a $>10$-letter gain in BCVA from baseline, suggesting that retinal edema may significantly improve or resolve spontaneously in some patients, with accompanying gains in visual acuity. However, the mean change in BCVA from baseline at the last available visit was only +0.9 letters. These results reinforce the need for treatment to improve BCVA in patients with DME. Prompt treatment is recommended, because there was evidence in the RISE/RIDE registration studies of ranibizumab that delay in anti-VEGF treatment of DME may lead to worse outcomes [24]. 


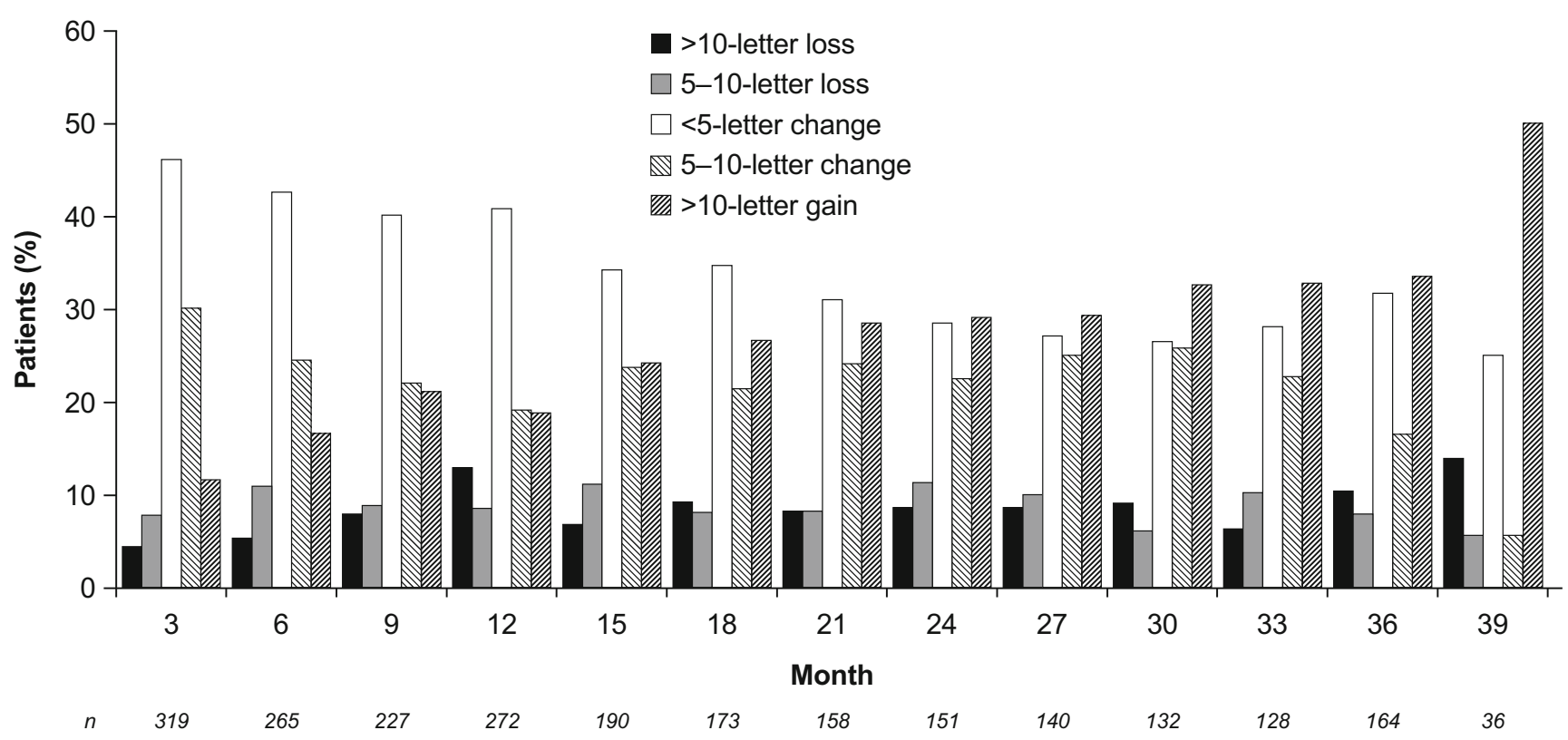

Fig. 3 Frequency distribution of the change in BCVA from baseline in the study eye of sham-treated patients. Analysis is based on observed values with no imputation for missing values. BCVA, best-corrected visual acuity

The requirement for patient discontinuation from the study before receiving rescue treatment influenced the mean changes in BCVA and CRT from baseline that were observed in the second and the third year of follow-up, because patients with poor outcomes frequently exited the study early. The missing data from these patients led to apparent improvements in visual and anatomic outcomes that did not reflect the natural history of DME in the total sham group, but instead reflect the natural history of DME in the subgroup of patients who did not discontinue from the study because of lack of efficacy or other reasons. To use data from as many patients in the sham group as possible, despite the high rate of discontinuations, the endpoints chosen for the models evaluating potential baseline and systemic factors associated with patient visual and anatomic outcomes were BCVA and CRT at the last visit with

$\begin{array}{lllllllllllllll}n & 342 & 311 & 255 & 218 & 214 & 181 & 166 & 153 & 146 & 133 & 127 & 122 & 141 & 35\end{array}$

Month

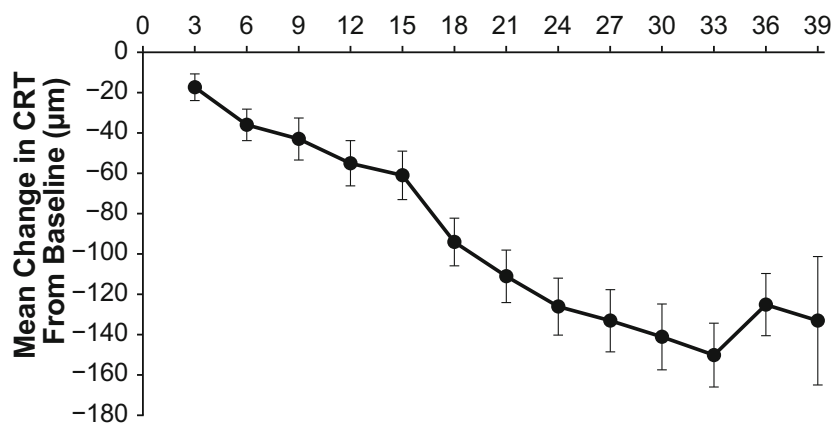

Fig. 4 Mean change in CRT from baseline in the study eye of shamtreated patients. Mean baseline CRT was $451 \mu \mathrm{m}$. Analysis is based on observed values with no imputation for missing values. Error bars indicate the standard error of the mean. CRT, central retinal thickness available data (rather than at month 36/39) and average change in BCVA from baseline across the study period.

Several studies have suggested a relationship between use of glitazones and the occurrence of DME $[10,11]$, but findings have been inconsistent, with a large longitudinal study reporting no significant association between glitazone use and the incidence of DME in type 2 diabetes patients [25]. In the MEAD study, the availability of repeated clinical assessments over a period of 3 years allowed the evaluation of potential risk factors for the improvement or aggravation of DME. A total of $55(15.7 \%)$ patients in the sham group used a glitazone during the study period. Our analysis found no association

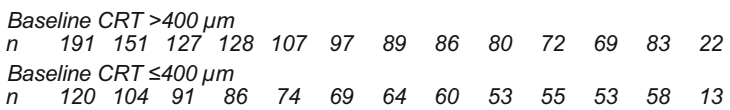

\section{Month}

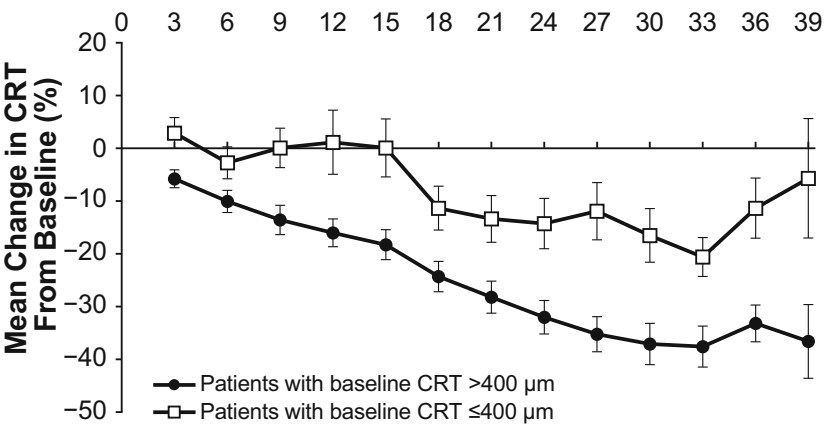

Fig. 5 Mean percentage change in CRT from baseline in the study eye of sham-treated patients stratified by baseline CRT. Analysis is based on observed values with no imputation for missing values. Error bars indicate the standard error of the mean. CRT, central retinal thickness 
Table 3 Full model of predictors of BCVA change from baseline (letters) at the last available visit

\begin{tabular}{|c|c|c|c|}
\hline Parameter & Estimate & Standard error & $P$ value \\
\hline \multicolumn{4}{|l|}{ Baseline patient characteristic } \\
\hline Sex, female & 1.007 & 1.559 & 0.519 \\
\hline Age, years & -0.181 & 0.079 & 0.023 \\
\hline \multicolumn{4}{|l|}{ Race/ethnicity } \\
\hline Caucasian & 7.494 & 4.550 & 0.101 \\
\hline Black & 8.833 & 5.456 & 0.107 \\
\hline Asian (not Japanese) & 10.111 & 4.880 & 0.039 \\
\hline Hispanic & 5.344 & 5.079 & 0.294 \\
\hline Japanese & -5.222 & 14.087 & 0.711 \\
\hline BMI & 0.013 & 0.131 & 0.922 \\
\hline $\mathrm{HbA} 1 \mathrm{c} \leq 8 \%$ & 0.363 & 1.672 & 0.828 \\
\hline Systolic blood pressure, $\mathrm{mm} \mathrm{Hg}$ & 0.044 & 0.043 & 0.305 \\
\hline Diastolic blood pressure, $\mathrm{mm} \mathrm{Hg}$ & 0.087 & 0.073 & 0.235 \\
\hline Glomerular filtration rate, $\mathrm{mL} / \mathrm{min}$ & 0.043 & 0.030 & 0.151 \\
\hline History of hypertension & -1.808 & 1.730 & 0.297 \\
\hline History of hypercholesterolemia & 0.154 & 1.713 & 0.929 \\
\hline Duration of diabetes, years & 0.000 & 0.085 & 0.996 \\
\hline \multicolumn{4}{|l|}{ Baseline study eye characteristic } \\
\hline Phakic lens status & 0.115 & 1.707 & 0.946 \\
\hline No prior DME treatment & -2.517 & 1.721 & 0.145 \\
\hline DR severity score $\leq 6$ & 2.468 & 1.557 & 0.114 \\
\hline BCVA & -0.188 & 0.087 & 0.031 \\
\hline Duration of DME, months & 0.023 & 0.027 & 0.390 \\
\hline \multicolumn{4}{|l|}{ During study period } \\
\hline No concomitant use of platelet aggregation inhibitor & -1.362 & 1.571 & 0.387 \\
\hline No concomitant use of glitazone & -0.275 & 2.088 & 0.895 \\
\hline No concomitant use of medication to treat dyslipidemia & -2.359 & 1.557 & 0.131 \\
\hline Number of antihypertensive medications used & 0.257 & 0.611 & 0.674 \\
\hline Adverse event report(s) of dyslipidemia & 3.169 & 3.253 & 0.331 \\
\hline Change in $\mathrm{HbA} 1 \mathrm{c}$ from baseline at last visit & 19.942 & 66.249 & 0.764 \\
\hline
\end{tabular}

$B C V A$ best-corrected visual acuity, $B M I$ body mass index, $D M E$ diabetic macular edema, $D R$ diabetic retinopathy, $H b A l c$ glycosylated hemoglobin between use of glitazones during the study and the average change in BCVA from baseline, or between use of glitazones during the study and the change in BCVA or CRT from baseline at the last available visit.

Table 4 Final model after stepwise selection of predictors of BCVA change from baseline (letters) at the last available visit

\begin{tabular}{lrll}
\hline Parameter & Estimate & Standard error & $P$ value \\
\hline Baseline patient characteristic & & & \\
Age, years & -0.289 & 0.095 & 0.003 \\
History of hypertension & -5.847 & 2.596 & 0.025 \\
Baseline study eye characteristic & & \\
DR severity score $\leq 6$ & 4.312 & 1.849 & 0.021 \\
BCVA & -0.277 & 0.105 & 0.009 \\
\hline
\end{tabular}

$B C V A$ best-corrected visual acuity, $D R$ diabetic retinopathy
It is well accepted that maintaining low $\mathrm{HbAlc}$ levels and near-normal blood pressure lowers the risk of the development and progression of DR [26]. However, there is a lack of evidence that interventions to reduce blood pressure are effective in reducing the risk of clinically significant DME [27]. In our analysis, history of hypertension was a significant factor predicting less improvement in BCVA at the last available visit, but was not significant in the model for average change in BCVA over the study period. Interestingly, the number of antihypertensive medications used during the study had a significant association with the reduction in CRT at the last available visit, suggesting that interventions to reduce blood pressure might be helpful in reducing retina edema.

There is evidence of a possible association between serum lipids and DME $[4,5]$, and studies have further suggested that use of lipid-lowering medications might reduce the incidence 
Table 5 Full model of predictors of average BCVA change from baseline (letters, using the timeadjusted area-under-the-curve approach)

\begin{tabular}{|c|c|c|c|}
\hline Parameter & Estimate & Standard error & $P$ value \\
\hline \multicolumn{4}{|l|}{ Baseline patient characteristic } \\
\hline Sex, female & 0.964 & 1.264 & 0.446 \\
\hline Age, years & -0.096 & 0.064 & 0.137 \\
\hline \multicolumn{4}{|l|}{ Race/ethnicity } \\
\hline Caucasian & 6.809 & 3.737 & 0.069 \\
\hline Black & 8.481 & 4.484 & 0.060 \\
\hline Asian & 8.394 & 4.003 & 0.037 \\
\hline Hispanic & 3.915 & 4.144 & 0.346 \\
\hline Japanese & -5.662 & 11.577 & 0.625 \\
\hline BMI & -0.002 & 0.106 & 0.985 \\
\hline $\mathrm{HbA} 1 \mathrm{c} \leq 8 \%$ & 0.145 & 1.352 & 0.915 \\
\hline Systolic blood pressure, $\mathrm{mm} \mathrm{Hg}$ & 0.018 & 0.035 & 0.612 \\
\hline Diastolic blood pressure, $\mathrm{mm} \mathrm{Hg}$ & 0.028 & 0.060 & 0.635 \\
\hline Glomerular filtration rate, $\mathrm{mL} / \mathrm{min}$ & 0.042 & 0.025 & 0.086 \\
\hline History of hypertension & -0.777 & 1.420 & 0.585 \\
\hline History of hypercholesterolemia & 0.109 & 1.404 & 0.938 \\
\hline Duration of diabetes, years & -0.018 & 0.069 & 0.794 \\
\hline \multicolumn{4}{|l|}{ Baseline study eye characteristic } \\
\hline Phakic lens status & -0.064 & 1.383 & 0.963 \\
\hline No prior DME treatment & -2.353 & 1.392 & 0.092 \\
\hline DR severity score $\leq 6$ & 2.003 & 1.266 & 0.115 \\
\hline BCVA & -0.187 & 0.070 & 0.008 \\
\hline Duration of DME, months & 0.021 & 0.022 & 0.350 \\
\hline \multicolumn{4}{|l|}{ During study period } \\
\hline No concomitant use of platelet aggregation inhibitor & -0.826 & 1.272 & 0.517 \\
\hline No concomitant use of glitazone & -0.042 & 1.675 & 0.980 \\
\hline No concomitant use of medication to treat dyslipidemia & -2.195 & 1.263 & 0.083 \\
\hline Number of antihypertensive medications used & 0.380 & 0.492 & 0.441 \\
\hline Adverse event report(s) of dyslipidemia & 0.961 & 2.552 & 0.707 \\
\hline Change in $\mathrm{HbA} 1 \mathrm{c}$ from baseline at last visit & 62.884 & 53.103 & 0.237 \\
\hline
\end{tabular}

$B C V A$ best-corrected visual acuity, $B M I$ body mass index, $D M E$ diabetic macular edema, $D R$ diabetic retinopathy, $H b A l c$ glycosylated hemoglobin of DME [6, 28]. A study in 1011 patients with type 2 diabetes showed a relationship between lipid profiles and $\mathrm{HbA} 1 \mathrm{c}$ levels [29]. Serum triglyceride levels were significantly higher and levels of high-density lipoprotein were significantly lower

Table 6 Final model after stepwise selection of predictors of average BCVA change from baseline (letters, using the time-adjusted area-underthe-curve approach)

\begin{tabular}{|c|c|c|c|}
\hline Parameter & Estimate & Standard error & $P$ value \\
\hline \multicolumn{4}{|c|}{ Baseline patient characteristic } \\
\hline Age, years & -0.164 & 0.078 & 0.035 \\
\hline \multicolumn{4}{|c|}{ Baseline study eye characteristic } \\
\hline DR severity score $\leq 6$ & 3.164 & 1.515 & 0.038 \\
\hline BCVA & -0.210 & 0.086 & 0.015 \\
\hline
\end{tabular}

$B C V A$ best-corrected visual acuity, $D R$ diabetic retinopathy in patients with $\mathrm{HbA} 1 \mathrm{c} \leq 6 \%$ compared with patients with HbAlc $>6 \%$ [29]. Therefore, a possible confounding effect of hyperglycemia on serum lipids needs to be considered when evaluating the relationship between lipid profiles and DME. In our analysis, history of hypercholesterolemia, adverse event reports of dyslipidemia during the study, and use of medications to treat dyslipidemia during the study were not significant independent risk factors predicting BCVA or CRT outcomes. However, in the full model of average BCVA change (AUC approach), there was a trend for an association between use of medications to treat dyslipidemia and a 2.2letter larger gain in BCVA $(P=0.083)$.

A recent study similar to the present study reported factors associated with BCVA and CRT outcomes at month 24 in patients treated with monthly sham injections in the RISE/RIDE trials [30]. Higher baseline BCVA, thinner 
Table 7 Full model of predictors of CRT reduction from baseline $(\mu \mathrm{m})$ at the last available visit

\begin{tabular}{|c|c|c|c|}
\hline Parameter & Estimate & Standard error & $P$ value \\
\hline \multicolumn{4}{|l|}{ Baseline patient characteristic } \\
\hline Sex, female & -4.974 & 21.499 & 0.817 \\
\hline Age, years & -0.649 & 1.098 & 0.555 \\
\hline \multicolumn{4}{|l|}{ Race/ethnicity ${ }^{\mathrm{a}}$} \\
\hline Caucasian & -5.785 & 60.011 & 0.923 \\
\hline Black & -37.333 & 73.357 & 0.611 \\
\hline Asian & 77.405 & 64.668 & 0.232 \\
\hline Hispanic & -43.613 & 68.438 & 0.525 \\
\hline BMI & 0.835 & 1.805 & 0.644 \\
\hline $\mathrm{HbA} 1 \mathrm{c} \leq 8 \%$ & 27.699 & 22.968 & 0.229 \\
\hline Systolic blood pressure, $\mathrm{mm} \mathrm{Hg}$ & -0.245 & 0.634 & 0.699 \\
\hline Diastolic blood pressure, $\mathrm{mm} \mathrm{Hg}$ & 0.556 & 1.052 & 0.598 \\
\hline Glomerular filtration rate, $\mathrm{mL} / \mathrm{min}$ & -0.855 & 0.404 & 0.035 \\
\hline No history of hypertension & -25.851 & 23.990 & 0.282 \\
\hline No history of hypercholesterolemia & 6.396 & 23.538 & 0.786 \\
\hline Duration of diabetes, years & -0.278 & 1.178 & 0.814 \\
\hline \multicolumn{4}{|l|}{ Baseline study eye characteristic } \\
\hline Phakic lens status & -11.551 & 23.263 & 0.620 \\
\hline No prior DME treatment & -19.447 & 23.704 & 0.413 \\
\hline DR severity score $\leq 6$ & -32.081 & 20.977 & 0.127 \\
\hline $\mathrm{CRT}, \mu \mathrm{m}$ & 0.323 & 0.075 & $<0.001$ \\
\hline Duration of DME, months & 0.072 & 0.362 & 0.843 \\
\hline \multicolumn{4}{|l|}{ During study period } \\
\hline No concomitant use of platelet aggregation inhibitor & -6.746 & 21.683 & 0.756 \\
\hline No concomitant use of glitazone & -14.687 & 29.191 & 0.615 \\
\hline No concomitant use of medication to treat dyslipidemia & -6.181 & 21.498 & 0.774 \\
\hline Number of antihypertensive medications used & 14.306 & 8.034 & 0.076 \\
\hline No adverse event report(s) of dyslipidemia & -48.901 & 44.497 & 0.273 \\
\hline Change in $\mathrm{HbA} 1 \mathrm{c}$ from baseline at last visit & 874.464 & 882.141 & 0.322 \\
\hline
\end{tabular}

$B M I$ body mass index, $C R T$ central retinal thickness, $D M E$ diabetic macular edema, $D R$ diabetic retinopathy, $H b A l c$ glycosylated hemoglobin

${ }^{\text {a }}$ Japanese race (one patient) was not included in the model because the patient had missing CRT data baseline CRT, absence of history of renal disease, and baseline presence of hard exudates in the center subfield were associated with good BCVA (20/40 or better) at month 24 ; younger age, lower baseline BCVA, and thinner baseline CRT were associated with achievement of $\mathrm{a} \geq 15$-letter gain in BCVA from baseline at month 24; lower baseline BCVA, absence of history of hypercholesterolemia, history of retinal disease, and presence of intraretinal cysts were associated with poor BCVA (20/100 or worse) at month 24; presence of intraretinal cysts, presence of subretinal fluid, and history of renal disease
Table 8 Final model after stepwise selection of predictors of CRT reduction from baseline $(\mu \mathrm{m})$ at the last available visit

\begin{tabular}{lccc}
\hline Parameter & Estimate & Standard error & $P$ value \\
\hline Baseline patient characteristic & & & 0.008 \\
$\quad$ Age, years & -3.240 & 1.201 & 0.014 \\
$\quad$ Glomerular filtration rate, $\mathrm{mL} / \mathrm{min}$ & -1.098 & 0.442 & $<0.001$ \\
Baseline study eye characteristic & 0.456 & 0.083 & \\
CRT, $\mu \mathrm{m}$ & & & 0.039 \\
During study period & 16.212 & 7.809 & \\
$\quad$ Number of antihypertensive medications used & & &
\end{tabular}

$C R T$ central retinal thickness 
were associated with $\mathrm{a} \geq 1$ 5-letter loss in BCVA from baseline at month 24; and lower baseline BCVA, thinner baseline CRT, and statin use were associated with resolution of edema (CRT $\leq 250 \mu \mathrm{m})$ at month 24 [30]. The study population in RISE/RIDE [16] appeared similar in baseline characteristics to the study population in MEAD [19]; however, laser rescue treatment was allowed in RISE/RIDE, and sham-treated patients received a mean of 1.6 (RIDE) or 8.8 (RISE) laser treatments (range 0-7) between study baseline and month 24 [16]. The extent to which laser treatments may have affected outcomes and the identification of prognostic factors for outcomes in the sham group of RISE/RIDE is unknown.

Consistent with the report from the RISE/RIDE studies, our analysis identified older age as a significant factor associated with worse improvement in BCVA from baseline across the follow-up period and at the last visit with available data. Consistent with these findings, older age was also associated with worse improvement in CRT from baseline at the last visit with available data.

Our evaluation of factors associated with outcomes in sham-treated patients with DME in the MEAD study had several limitations. Because of the limited size of the study population and the patient selection criteria used in the MEAD study, not all factors that have been reported to be risk factors for DME, or that are likely to exacerbate DME, could be investigated. For example, pregnancy is a potential risk factor for DME [7], but women who were pregnant or could potentially become pregnant were excluded from MEAD. In addition, both obstructive sleep apnea [7] and anemia [31] have been reported to be risk factors for DME, yet the numbers of patients with sleep apnea and anemia in the sham group in the MEAD study were too small for meaningful analysis. The number of patients with vitreomacular adhesion similarly was too small for meaningful analysis. Laboratory data on serum lipid profiles were not collected, so any association between lipid profiles and exacerbation of DME could not be investigated. Finally, patients with $\mathrm{HbAlc}>10 \%$ or GFR $<50 \mathrm{~mL} / \mathrm{min}$ were excluded from the study, and patients in the study were monitored frequently and were encouraged to control their diabetes. This likely limited our ability to detect the influence of glycemic control and nephropathy on outcomes. Our findings are applicable to patients with characteristics similar to those of the patients who participated in the MEAD study, i.e., patients with center-involved DME who do not have uncontrolled diabetes, uncontrolled other systemic disease, or active retinal neovascularization.

Because many patients with poor outcomes exited the study early, it is difficult to draw conclusions regarding the overall vision of the untreated sham-control group. The last available data for patients showed a mean change in BCVA from baseline of +0.9 letters, with $37.5 \%$ of patients having no change in BCVA from baseline. Furthermore, visual outcomes in this group may not reflect the natural history of DME in a broader patient population, because glycemic control is likely to be improved in patients enrolled in a clinical trial. With the advent of anti-VEGF therapies and long-acting dexamethasone implants, the vision of diabetics with central macular edema has significantly improved. The sham-treated group in the MEAD study has shown the importance of hypertension, renal disease, and starting vision and CRT as markers for progression. Older age and baseline DR score $>6$ were identified as significant risk factors for worse average change in BCVA across the study period. Thicker baseline CRT and a larger number of antihypertensive medications used were significant factors associated with better improvement in CRT during the study period.

Acknowledgments Writing and editorial assistance was provided to the authors by Kate Ivins, PhD, of Evidence Scientific Solutions, Philadelphia, PA, and funded by Allergan plc. All authors met the ICMJE authorship criteria. Neither honoraria nor payments were made for authorship.

Funding information This study was sponsored by Allergan plc, Dublin, Ireland. Y.H. Yoon, D.S. Boyer, R.K. Maturi, F. Bandello, and R. Belfort Jr. are consultants to Allergan. A.J. Augustin has received research support and speaker fees from Allergan. X.-Y. Li, Z. Bai, and Y. Hashad are employees of Allergan. The authors have full control of all primary data and they agree to allow Graefe's Archive for Clinical and Experimental Ophthalmology to review their data upon request.

\section{Compliance with ethical standards}

Ethical approval All procedures performed in studies involving human participants were in accordance with the ethical standards of the institutional and/or national research committee and with the 1964 Helsinki declaration and its later amendments or comparable ethical standards.

Informed consent Informed consent was obtained from all individual participants included in the study.

\section{Appendix 1}

The MEAD Study Group Principal Investigators

Suel Abujamra (Eye Clinic Doctor Suel Abujamra, São Paulo, Brazil), James Acton (Dr J Acton, Cape Town, South Africa), Fareed Ali (Canadian Centre for Advanced Eye Therapeutics, Mississauga, ON, Canada), Andrew Antoszyk (Charlotte Eye Ear Nose \& Throat Associates, Charlotte, NC, USA), Albert J. Augustin (Städtisches Klinikum Karlsruhe, Karlsruhe, Germany), Carl C. Awh (Tennessee Retina, Nashville, TN, USA), Adiel Barak (Tel Aviv Medical Center, Tel Aviv, Israel), Karl Ulrich Bartz-Schmidt (University Eye Hospital Tübingen, Tübingen, Germany), Caroline R. Baumal (Tufts Medical Center, Boston, MA, USA), Rubens Belfort, Jr. (Federal University of São Paulo, São Paulo, Brazil), Muna Bhende (Sankara Nethralaya, Chennai, Tamil Nadu, India), David S. Boyer (Retina- 
Vitreous Associates Medical Group, Los Angeles, CA, USA), William Z. Bridges, Jr. (Western Carolina Retinal Associates, Asheville, NC, USA), David M. Brown (Vitreoretinal Consultants, Houston, TX, USA), Trevor Carmichael (Wits Donald Gordon Medical Centre, Johannesburg, South Africa), Ken Carnevale (Ophthalmic Consultants of Long Island, Lynbrook, NY, USA), Antonio M. Casella (Federal University of Londrina, Londrina, Paraná, Brazil), Tom Chang (Doheny Eye Institute, Los Angeles, CA, USA), Daniel Chechik (Henkind Eye Institute, Bronx, NY, USA), San-Ni Chen (Changhua Christian Hospital, Changhua, Taiwan), Lawrence P. Chong (Doheny Eye Institute, Los Angeles, CA, USA), Victor Chong (King's College Hospital, London, UK), Joel Corwin (Miramar Eye Specialists Medical Group, Ventura, CA, USA), Catherine Creuzot-Garcher (Hôpital de Dijon, Dijon, France), Alan Cruess (Capital Health, Halifax, NS, Canada), Mark Daniell (Royal Melbourne Hospital, Parkville, VIC, Australia), Marcos P. de Avila (Brazilian Center for Eye Surgery, Goiânia, Goiás, Brazil), Haroldo Vieira de Moraes, Jr. (Hospital Universitário Clementino Fraga Filho, Rio de Janeiro, Brazil), Robert G. Devenyi (Toronto Western Hospital, Toronto, ON, Canada), Bernard H. Doft (Retina Vitreous Consultants, Pittsburgh, PA, USA), Mark Donaldson (Greenlane Clinical Centre, Epsom, Auckland, New Zealand), Richard Dreyer (Retina Northwest PC, Portland, OR, USA), Dean Eliott (Doheny Eye Institute, Los Angeles, CA, USA), Harry M. Engel (Henkind Eye Institute, Bronx, NY, USA), Jan Ernest (Central Military Hospital, Prague, Czech Republic), Thomas F. Essman (Mercy Clinic Eye Specialists, Springfield, MO, USA), Philip M. Falcone (Connecticut Retina Consultants, Bridgeport, CT, USA), Sharon Fekrat (Duke University Eye Center, Durham, NC, USA), Joseph R. Ferencz (Meir Medical Center, Kfar-Saba, Israel), Joao L. Ferreira (Vista Medicina dos Olhos, Florianópolis, SC, Brazil), Joao Figueira (Association for Innovation and Biomedical Research on Light and Image, Coimbra, Portugal), Ivan Fiser (Cornea Lexum Eye Clinic, Prague, Czech Republic), Bradley Foster (New England Retina Consultants, Springfield, MA, USA), Gregory M. Fox (Retina Associates PA, Shawnee Mission, KS, USA), William R. Freeman (UC San Diego Jacobs Retina Center, La Jolla, CA, USA), S. P. Garg (Dr. Rajendra Prasad Centre for Ophthalmic Sciences, New Delhi, India), Mark Gillies (Sydney Eye Hospital, Sydney, NSW, Australia), David Glaser (Retina Associates of St. Louis, Florissant, MO, USA), Burton G. Goldstein (University of South Florida Ophthalmology Department, Tampa, FL, USA), Andre M. V. Gomes (Eye Clinic Doctor Suel Abujamra, São Paulo, Brazil), John R. Gonder (Ivey Eye Institute, London, ON, Canada), Lingam Gopal (Sankara Nethralaya, Chennai, Tamil Nadu, India), Petrus Gous (Pretoria Eye Institute, Arcadia, Pretoria, South Africa), Amod Gupta (Advanced
Eye Care Centre, Chandigarh, India), Anurag Gupta (Doris Stein Eye Research Center, Los Angeles, CA, USA), Lawrence Halperin (Retina Group of Florida, Ft. Lauderdale, FL, USA), Dennis Han (Eye Institute/Medical College of Wisconsin, Milwaukee, WI, USA), Seenu M. Hariprasad (University of Chicago Department of Ophthalmology and Visual Science, Chicago, IL, USA), Frank G. Holz (University of Bonn, Bonn, Germany), Peter Kaiser (Cleveland Clinic Foundation, Cleveland, OH, USA), Bohdana Kalvodova (General Teaching Hospital Ophthalmology Clinic, Prague, Czech Republic), Barrett Katz (Henkind Eye Institute, Bronx, NY, USA), Randy S. Katz (Florida Eye Microsurgical Institute, Boynton Beach, FL, USA), Dariusz Kęcik (Medical University of Warsaw, Warsaw, Poland), Judianne Kellaway (Texas Medical Center, Houston, TX, USA), Itamar Klemperer (Soroka University Medical Center, Beer-Sheva, Israel), Baruch Kuppermann (University of California Irvine Medical Center, Orange, CA, USA), Paolo Lanzetta (University Hospital University of Udine, Udine, Italy), Rosangela Lattanzio (San Raffaele Foundation of Monte Tabor, Milan, Italy), Won-Ki Lee (Catholic University of Korea St Mary's Hospital, Seoul, South Korea), John Lehr (Magruder Eye Institute, Orlando, FL, USA), Monique Leys (West Virginia University Eye Institute, Morgantown, WV, USA), Isaac Loose (Retina Research Center, Austin, TX, USA), Andrew Lotery (Southampton General Hospital, Southampton, UK), DaWen Lu (Tri-Service General Hospital, Taipei, Taiwan), Paul McCartney (Hobart Eye Surgeons, Hobart, TAS, Australia), Ajit B. Majji (L V Prasad Eye Institute, Hyderabad, Andhra Pradesh, India), Jose A. Martinez (Austin Retina Associates, Austin, TX, USA), Pascale Massin (National Hospital of Ophthalmology [CHNO] of Quinze-Vingts, Paris, France), Raj K. Maturi (Midwest Eye Institute, Indianapolis, IN, USA), Ugo Menchini (Careggi University Hospital, Florence, Italy), Geeta Menon (Frimley Park Hospital, Camberley, Surrey, UK), Mark Michels (Retina Care Specialists, Palm Beach Gardens, FL, USA), Edoardo Midena (Padova University Hospital, Padua, Italy), James Miller, Jr. (Southeastern Retina Associates, Knoxville, TN, USA), Paul Mitchell (Westmead Eye Clinic of Westmead Hospital, Westmead, NSW, Australia), Joseph Moisseiev (Goldschleger Eye Institute of Sheba Medical Centre, Tel HaShomer, Israel), Lawrence Morse (UC Davis Medical Center, Sacramento, CA, USA), Rafael Navarro (Instituto de Microcirugia Ocular, Barcelona, Spain), Janos Nemeth (Semmelweis University, Budapest, Hungary), Henry Newland (Royal Adelaide Hospital, Adelaide, SA, Australia), Richard Newsom (Southampton General Hospital, Southampton, UK), John Nichols (University of Arizona, Tucson, AZ, USA), Juan Orellana (Virginia Commonwealth University, Richmond, VA, USA), Nicola Orzalesi (San Paolo Hospital, Milan, Italy), Augusto 
Paranhos, Jr. (Hospital Israelita Albert Einstein, São Paulo, Brazil), Robert Park (University of Arizona, Tucson, AZ, USA), Susanna Park (UC Davis Medical Center, Sacramento, CA, USA), Maurizio Battaglia Parodi (Eye Clinic of the University of Trieste, Trieste, Italy), Peter R. Pavan (University of South Florida Ophthalmology Department, Tampa, FL, USA), James Peace (United Medical Research Institute, Inglewood, CA, USA), Don J. Perez-Ortiz (Perez Eye Center, Tampa, FL, USA), Ayala Pollack (Kaplan Medical Center, Rehovet, Israel), Kim Ramaswamy (Aravind Eye Hospital, Tamil Nadu, India), Ramakrishna Ratnakaram (University of Florida, Gainesville, FL, USA), Giuseppe Ravalico (Eye Clinic of the University of Trieste, Trieste, Italy), Jiri Rehak (University Hospital Olomouc, Olomouc, Czech Republic), Kourous Rezaei (University of Chicago Department of Ophthalmology and Visual Science, Chicago, IL, USA), Stanislao Rizzo (Pisana University Hospital, Pisa, Italy), Francisco J. Rodriguez-Alvira (Fundación Oftalmológica Nacional, Bogotá, Colombia), Jean-Paul Romanet (Grenoble University Hospital Centre, Grenoble, France), Steven Rose (Rochester Ophthalmological Group, Rochester, NY, USA), Richard B. Rosen (New York Eye and Ear Infirmary, New York, NY, USA), Luca Rossetti (San Paolo Hospital, Milan, Italy), José Maria Ruiz-Moreno (VISSUM Ophthalmological Institute of Alicante, Alicante, Spain), SriniVas Sadda (Doheny Eye Institute, Los Angeles, CA, USA), Kenneth Sall (Sall Research Medical Center, Artesia, CA, USA), Dirk Sandner (University Eye Clinic Dresden, Dresden, Germany), Alvaro Fernandez-Vega Sanz (Instituto Oftalmológico de Alicante-Vissum, Alicante, Spain), Gil Sartani (HaEmek Medical Center, Afula, Israel), Stefanie Schmickler (Augenärzte Gemeinschaftspraxis, Ahaus, Germany), Steven D. Schwartz (Doris Stein Eye Research Center, Los Angeles, CA, USA), Y. R. Sharma (Dr. Rajendra Prasad Centre for Ophthalmic Sciences, New Delhi, India), Shwu-Jiuan Sheu (Veterans General HospitalKaohsiung, Kaohsiung, Taiwan), Michael Singer (Medical Center Ophthalmology Associates, San Antonio, TX, USA), Sobha Sivaprasad (King's College Hospital, London, UK), Gisele Soubrane (Centre Hospitalier Intercommunal de Créteil, Créteil, France), Petr Soucek (University Hospital Kralovske, Prague, Czech Republic), Eric H. Souied (Centre Hospitalier Intercommunal de Créteil, Créteil, France), Giovanni Staurenghi (Luigi Sacco Hospital, Milan, Italy), Jan Studnicka (Eye Clinic of the University Hospital in Hradec Králové, Hradec Králové, Czech Republic), Marta Suarez-Figueroa (Hospital Oftalmológico de MadridVissum, Madrid, Spain), Walter Y. Takahashi (University of São Paulo Faculty of Medicine Clinics Hospital, São Paulo, Brazil), Daniele Tognetto (Eye Clinic of the University of Trieste, Trieste, Italy), Patrick L. Tsai (University of Arizona, Tucson, AZ, USA), Lawrence J. Ulanski, II
(University of Illinois at Chicago, Chicago, IL, USA), Harvey S. Uy (Asian Eye Institute, Makati, Philippines), Monica Varano (G.B. Bietti Foundation for Study and Research in Ophthalmology, Rome, Italy), Miroslav Veith (University Hospital Kralovske, Prague, Czech Republic), Igor Vicha (Ophthalmology Clinic of the Faculty Hospital Brno, Brno, Czech Republic), Francesco Viola (Ospedale Maggiore Policlinico Mangiagalli e Regina Elena, Milan, Italy), Linda Visser (University of KwaZulu-Natal, Durban, South Africa), Dov Weinberger (Rabin Medical Center, Petah Tikva, Israel), Glenn L. Wing (National Ophthalmic Research Institute, Fort Myers, FL, USA), Edmund Wong (Singapore National Eye Centre, Singapore, Singapore), Tien Y. Wong (Royal Victorian Eye and Ear Hospital, East Melbourne, VIC, Australia), Edward Wylęgała (District Railway Hospital in Katowice, Katowice, Poland), Jiong Yan (Emory University Eye Center, Atlanta, GA, USA), Young Hee Yoon (Asan Medical Center, Seoul, South Korea), Lucy H. Young (Massachusetts Eye and Ear Infirmary, Boston, MA, USA), Hyeong G. Yu (Seoul National University Hospital, Seoul, South Korea), Ingrid E. Zimmer-Galler (Johns Hopkins Wilmer Eye Institute, Baltimore, MD, USA).

\section{Appendix 2}

I. Platelet aggregation inhibitors (includes acetic acid derivatives and related substances, aminosalicylic acid and similar agents, anilides, anti-inflammatory and antirheumatic agents; heparin and similar agents; nonsteroidal antiinflammatory agents and preparations, other antiinflammatory and antirheumatic agents, platelet aggregation inhibitors excluding heparin, proprionic acid derivatives, and salicylic acid and derivatives)

Abciximab; aceclofenac; acetametacin; acetylsalicylate lysine; acetylsalicyclic acid; Algiril; Arthrotec; Asasantin; Ascriptin; aspirin; Axotal; bromefenac sodium; Bufferin; certoparin sodium; cilostazol; clopidogrel; clopidogrel bisulfate; Co-Advil; Couldina; dalteparin sodium; dexibuprofen; dexketoprofen trometamol; diclofenac; diclofenac diethylamine; diclofenac potassium; diclofenac sodium; dicolfenac; dicolfenac sodium; dipyridamole; Dolmina; DoppelSplat; enoxaparin; enoxaparin sodium; eptifibatide; etodolac; Flukit; flurbiprofen; flurbiprofin sodium; glucosamine; glucosamine sulfate; glucosamine w/chondroitin sulfate; heparin; heparin beraprost sodium; heparin calcium; heparin sodium; Ibupain; ibuprofen; ibuprofen arginine; ibuprofen w/paracetamol; Ilvico N; indobufen; indometacin; ketoprofen; ketorolac; ketorolac tromethamine; lonazolac; lonazolac calcium; loxoprofen; loxoprofen sodium; mesalazine; morniflumate; nabumetone; nadroparin; nadroparin 
calcium; naproxen; naproxen sodium; Nefazan Compuesto; nepafenac; niflumic acid; nimesulide; pantoprazole sodium; Paynocil; prosugrel hydrochloride; salicylates NOS; sarpogrelate; sarpogrelate hydrochloride; sesquihydrate; sulfasalazine; sulodexide; talniflumate; Thomapyrin N; ticlopidine; ticlopidine hydrochloride; triflusal; zaltoprofen

II. Glitazones.

Pioglitazone; pioglitazone hydrochloride; rosiglitazone, rosiglitazone maleate

III. Medications used to treat dyslipidemia (includes bile acid sequestrants, fibrates, HMG CoA reductase inhibitors and combinations, combinations of lipid modifying agents, nicotinic acid derivatives, and other lipid modifying agents)

Atchol-Asp; atorvastatin; atorvastatin calcium; Caduet; colesevelam hydrochloride; colestyramine; bezafibrate; Ecosprin Av; Epacaps; ezetimibe; gamolenic acid; fenofibrate; fish oil; fluvastatin; fluvastatin sodium; gemfibrozil; Lorlip; lovastatin; HMG CoA reductase inhibitors, other combinati; HMG CoA reduct. inhib. in comb. with oth. lipid $\mathrm{m}$; inegy; inositol nicotinate; lipid modifying agents, combinations; nicametate dihydrogen citrate; nicotinic acid; omega-3 fatty acids; omega-3 triglycerides; omega-3-acid ethyl ester; pitavastatin; pitavastatin calcium; policosanol; pravastatin; pravastatin sodium; rosuvastatin; rosuvastatin calcium; simvastatin; Zetitor

IV. Antihypertensive medications (includes ACE inhibitors, ACE inhibitors with calcium channel blockers, ACE inhibitors with diuretics, aldosterone antagonists, alphaadrenoreceptor antagonists, selective and nonselective beta blocking agents, mixed alpha and beta blocking agents, beta blocking agents with diuretics, thiazides, or other antihypertensive agents, angiotensin II antagonists, angiotensin II antagonists with calcium channel blockers or in other combinations, benzothiazepine derivatives, calcium channel blockers with diuretics, dihydropyridine derivatives, diuretics, enzymes, ergot alkaloids, highceiling diuretics and potassium-sparing agent, lowceiling diuretics and potassium-sparing agents; hydrazinophthalazine derivatives, imidazoline receptor agonists; imidazoline receptor agonists in combination with diuretics, methyldopa, nicotinic acid and derivatives, nitroferricyanide derivatives, other peripheral vasodilators, other potassium-sparing agents, phenylalkylamine derivatives, purine derivatives, rauwolfia alkaloids, renin-inhibitors, and thiazides)
ACE inhibitors; acebutolol; acebutolol hydrochloride; acetazolamide; Aldactazine; aldosterone antagonists; alfuzosin hydrochloride; aliskiren fumarate; amiloride; amlodipine; amlodipine besilate; amlodipine besylate w/ benazepril hydrochloride; amlodipine maleate; amlodipine w/ hydrochlorothiazide; amlodipine w/ valsartan; Amlong-A; angiotensin II antagonists and calcium channel blocker; angiotensin II antagonists and diuretics; Arkamin-H; atenolol; Azor; barnidipine hydrochloride; benazepril; bencyclane fumarate; bendroflumethiazide; Benicar HCT; benazepril hydrochloride; beta blocking agents and other diuretics; betaxolol hydrochloride; Bi Predonium; bisoprolol; bisoprolol fumarate; Blopress Plus; buflomedil; candesartan; candesartan cilexetil; captopril; carvedilol; celiprolol hydrochloride; Cibadrex; cilazapril; cilnidipine; cilostazol; clonidine; clonidine hydrochloride; Co-Betaloc; Co-diovan; delapril; diltiazem, diltiazem hydrochloride, Diovan Amlo; doxazosin; diuretics; doxazosin mesilate; Dyazide; Dynorm Plus; efonidipine; efonidipine hydrochloride; enalapril; enalapril maleate; enalapril maleate w/olercanidipin $\mathrm{HCl}$; enalaprilat; eprosartan mesilate; felodipine; Fixocard; fosinopril; fosinopril sodium; Gezor; guanfacine; hydralazine; hydralazine hydrochloride; hydrochlorothiazide; hydrochlorothiazide w/ losartan; Hyzaar; indapamide w/perindopril; inositol nicotinate; irbesartan; isradipine; kallidinogenase; Karvea HCT; labetalol; labetalol hydrochloride; lacidipine; lercanidipine; lercanidipine hydrochloride; lininopril; lisinopril dihydrate; Loram-H; losartan; losartan potassium; Lotar; manidipine hydrochloride; Met XL AM; methyclothiazide; methyldopa; metoprolol; metoprolol fumarate; metoprolol succinate; metoprolol tartrate; Moduretic; moxonidine; nadolol; naftidrofuryl oxalate; nebivolol hydrochloride; nicametate dihydrogen citrate; nicardipine; nicardipine hydrochloride; nicergoline; nicotinic acid; nifedipine; nimodipine; nitrendipine; nitroprusside sodium; olmesartan; olmesartan medoxomil; pentoxifylline; perindopril; perindopril arginine; perindopril erbumine; potassium canrenoate; prazosin; prazosin hydrochloride; PritorPlus; propranolol; propranolol hydrochloride; quinapril; quinapril hydrochloride; ramipril; raubasine; reserpine; rilmenidine; rilmenidine phosphate; telmisartan; Telsar-A O; theoesberiven; trandolapril; zofenopril calcium; Salutec; Seloken Comp; serrapeptase; sotalol; Spilactone-T; spironolactone; tamsulosin; tamsulosin hydrochloride; Tenoretic; Teram; terazosin; terazosin hydrochloride; Twynsta; Unimax; urapidil; valsartan; Vascoride; Vaseretic; verapamil; verapamil hydrochloride; vinburnine; xantinol nicotinate; Zestoretic 
Open Access This article is distributed under the terms of the Creative Commons Attribution 4.0 International License (http:// creativecommons.org/licenses/by/4.0/), which permits unrestricted use, distribution, and reproduction in any medium, provided you give appropriate credit to the original author(s) and the source, provide a link to the Creative Commons license, and indicate if changes were made.

\section{References}

1. Wong TY, Sun J, Kawasaki R et al (2018) Guidelines on diabetic eye care: the International Council of Ophthalmology recommendations for screening, follow-up, referral, and treatment based on resource settings. Ophthalmology 125:1608-1622

2. Romero-Aroca P, Baget-Bernaldiz M, Pareja-Rios A, LopezGalvez M, Navarro-Gil R, Verges R (2016) Diabetic macular edema pathophysiology: vasogenic versus inflammatory. J Diabetes Res 2016:2156273

3. Ou WC, Brown DM, Payne JF, Wykoff CC (2017) Relationship between visual acuity and retinal thickness during anti-vascular endothelial growth factor therapy for retinal diseases. Am J Ophthalmol 180:8-17

4. Yau JW, Rogers SL, Kawasaki R et al (2012) Global prevalence and major risk factors of diabetic retinopathy. Diabetes Care 35:556564

5. Miljanovic B, Glynn RJ, Nathan DM, Manson JE, Schaumberg DA (2004) A prospective study of serum lipids and risk of diabetic macular edema in type 1 diabetes. Diabetes 53:2883-2892

6. Kawasaki R, Konta T, Nishida K (2018) Lipid-lowering medication use is associated with decreased risk of diabetic retinopathy and its treatments in patients with type 2 diabetes: a real-world observational analysis of a health claims database. Diabetes Obes Metab 20:2351-2360

7. Diep TM, Tsui I (2013) Risk factors associated with diabetic macular edema. Diabetes Res Clin Pract 100:298-305

8. Perkovich BT, Meyers SM (1988) Systemic factors affecting diabetic macular edema. Am J Ophthalmol 105:211-212

9. Zhang X, Yang J, Zhong Y et al (2017) Association of bone metabolic markers with diabetic retinopathy and diabetic macular edema in elderly Chinese individuals with type 2 diabetes mellitus. Am J Med Sci 354:355-361

10. Ryan EH Jr, Han DP, Ramsay RC, Cantrill HL, Bennett SR, Dev S, Williams DF (2006) Diabetic macular edema associated with glitazone use. Retina 26:562-570

11. Fong DS, Contreras R (2009) Glitazone use associated with diabetic macular edema. Am J Ophthalmol 147:583-586.e1

12. Macky TA, Mahgoub MM (2013) The effect of glycemic control on visual and anatomic outcomes in response to therapy for diabetic macular edema. Eur J Ophthalmol 23:94-100

13. Yamada Y, Suzuma K, Ryu M, Tsuiki E, Fujikawa A, Kitaoka T (2013) Systemic factors influence the prognosis of diabetic macular edema after pars plana vitrectomy with internal limiting membrane peeling. Curr Eye Res 38:1261-1265

14. Matsuda S, Tam T, Singh RP, Kaiser PK, Petkovsek D, Carneiro G, Zanella MT, Ehlers JP (2014) The impact of metabolic parameters on clinical response to VEGF inhibitors for diabetic macular edema. J Diabetes Complicat 28:166-170

15. Singh RP, Habbu K, Ehlers JP, Lansang MC, Hill L, Stoilov I (2016) The impact of systemic factors on clinical response to ranibizumab for diabetic macular edema. Ophthalmology 123:1581-1587

16. Nguyen QD, Brown DM, Marcus DM et al (2012) Ranibizumab for diabetic macular edema: results from 2 phase III randomized trials: RISE and RIDE. Ophthalmology 119:789-801
17. Bansal AS, Khurana RN, Wieland MR, Wang PW, Van Everen SA, Tuomi L (2015) Influence of glycosylated hemoglobin on the efficacy of ranibizumab for diabetic macular edema: a post hoc analysis of the RIDE/RISE trials. Ophthalmology 122:1573-1579

18. American Diabetes Association (2014) Standards of medical care in diabetes - 2014. Diabetes Care 37(Suppl 1):S14-S80

19. Boyer DS, Yoon YH, Belfort R Jr, Bandello F, Maturi RK, Augustin AJ, Li XY, Cui H, Hashad Y, Whitcup SM, Ozurdex MEAD Study Group (2014) Three-year, randomized, shamcontrolled trial of dexamethasone intravitreal implant in patients with diabetic macular edema. Ophthalmology 121:1904-1914

20. Augustin AJ, Kuppermann BD, Lanzetta P, Loewenstein A, Li XY, Cui H, Hashad Y, Whitcup SM, Ozurdex MEAD Study Group (2015) Dexamethasone intravitreal implant in previously treated patients with diabetic macular edema: subgroup analysis of the MEAD study. BMC Ophthalmol 15:150

21. Danis RP, Sadda S, Li XY, Cui H, Hashad Y, Whitcup SM (2016) Anatomical effects of dexamethasone intravitreal implant in diabetic macular oedema: a pooled analysis of 3-year phase III trials. Br J Ophthalmol 100:796-801

22. Maturi RK, Pollack A, Uy HS, Varano M, Gomes AM, Li XY, Cui H, Lou J, Hashad Y, Whitcup SM, Ozurdex MEAD Study Group (2016) Intraocular pressure in patients with diabetic macular edema treated with dexamethasone intravitreal implant in the 3-year MEAD study. Retina 36:1143-1152

23. Early Treatment Diabetic Retinopathy Study Research Group (1991) Fundus photographic risk factors for progression of diabetic retinopathy. ETDRS report number 12. Ophthalmology 98(5 Suppl):823-833

24. Brown DM, Nguyen QD, Marcus DM et al (2013) Long-term outcomes of ranibizumab therapy for diabetic macular edema: the 36month results from two phase III trials: RISE and RIDE. Ophthalmology 120:2013-2022

25. Gower EW, Lovato JF, Ambrosius WT, Chew EY, Danis RP, Davis MD, Goff DC Jr, Greven CM, ACCORD Study Group (2018) Lack of longitudinal association between thiazolidinediones and incidence and progression of diabetic eye disease: the ACCORD Eye Study. Am J Ophthalmol 187:138-147

26. American Academy of Ophthalmology (2017) Diabetic Retinopathy Preferred Practice Pattern®_-updated 2017. https:// www.aao.org/preferred-practice-pattern/diabetic-retinopathy-pppupdated-2017. Accessed 11 December 2018

27. Do DV, Wang X, Vedula SS, Marrone M, Sleilati G, Hawkins BS, Frank RN (2015) Blood pressure control for diabetic retinopathy. Cochrane Database Syst Rev (1):CD006127

28. Shi R, Zhao L, Wang F, Liu F, Chen Z, Li R, Liu Y, Lin R (2018) Effects of lipid-lowering agents on diabetic retinopathy: a metaanalysis and systematic review. Int J Ophthalmol 11:287-295

29. Khan HA, Sobki SH, Khan SA (2007) Association between glycaemic control and serum lipids profile in type 2 diabetic patients: HbA1c predicts dyslipidaemia. Clin Exp Med 7:24-29

30. Sophie R, Lu N, Campochiaro PA (2015) Predictors of functional and anatomic outcomes in patients with diabetic macular edema treated with ranibizumab. Ophthalmology 122:1395-1401

31. Ajoy Mohan VK, Nithyanandam S, Idiculla J (2011) Microalbuminuria and low hemoglobin as risk factors for the occurrence and increasing severity of diabetic retinopathy. Indian $\mathrm{J}$ Ophthalmol 59:207-210

Publisher's note Springer Nature remains neutral with regard to jurisdictional claims in published maps and institutional affiliations. 